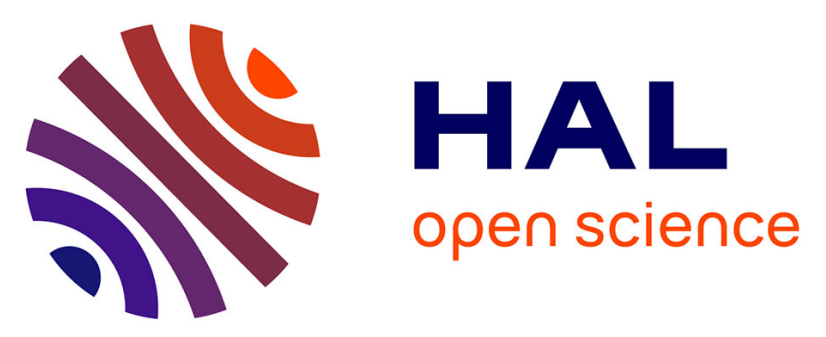

\title{
Influence of ultra-low ethylene partial pressure on microstructural and compositional evolution of sputter-deposited Zr-C thin films
}

Hicham Zaid, Angel Aleman, Koichi Tanaka, Chao Li, Pascal Berger, Tyson Back, Joshua Fankhauser, Mark S. Goorsky, Suneel Kodambaka

\section{To cite this version:}

Hicham Zaid, Angel Aleman, Koichi Tanaka, Chao Li, Pascal Berger, et al.. Influence of ultra-low ethylene partial pressure on microstructural and compositional evolution of sputter-deposited Zr-C thin films. Surface and Coatings Technology, 2020, 398, pp.126053. 10.1016/j.surfcoat.2020.126053 . cea-02884587

\section{HAL Id: cea-02884587 https://hal-cea.archives-ouvertes.fr/cea-02884587}

Submitted on 30 Jun 2020

HAL is a multi-disciplinary open access archive for the deposit and dissemination of scientific research documents, whether they are published or not. The documents may come from teaching and research institutions in France or abroad, or from public or private research centers.
L'archive ouverte pluridisciplinaire HAL, est destinée au dépôt et à la diffusion de documents scientifiques de niveau recherche, publiés ou non, émanant des établissements d'enseignement et de recherche français ou étrangers, des laboratoires publics ou privés. 


\title{
Influence of ultra-low ethylene partial pressure on microstructural and compositional evolution of sputter-deposited $\mathrm{Zr}$-C thin films
}

\author{
Hicham Zaid ${ }^{\mathrm{a}, *}$, Angel Aleman ${ }^{\mathrm{b}}$, Koichi Tanaka ${ }^{\mathrm{a}}$, Chao Li ${ }^{\mathrm{a}}$, Pascal Berger ${ }^{\mathrm{c}}$, Tyson Back ${ }^{\mathrm{d}}$, Josh \\ Fankhauser ${ }^{\mathrm{a}}$, Mark S. Goorsky ${ }^{\mathrm{a}}$, and Suneel Kodambaka ${ }^{\mathrm{a}}$ \\ ${ }^{a}$ Department of Materials Science and Engineering, University of California Los Angeles, 410 \\ Westwood Plaza, Los Angeles, CA 90095 USA \\ ${ }^{\mathrm{b}}$ Department of Mechanical and Aerospace Engineering, University of California Los Angeles, \\ 420 Westwood Plaza, Los Angeles, CA 90095 USA \\ c Université Paris-Saclay, CEA, CNRS, NIMBE, 91191, Gif-sur-Yvette, France \\ ${ }^{\mathrm{d}}$ Air Force Research Laboratory, Wright Patterson AFB, OH 45433-7707 \\ *email: hizaid@ucla.edu
}

\begin{abstract}
$\mathrm{Zr}-\mathrm{C}$ thin films are grown on single-crystalline $\mathrm{MgO}(001)$ substrates via ultra-high vacuum dc
\end{abstract} magnetron sputtering of $\mathrm{Zr}$ target in $10 \mathrm{mTorr} \mathrm{Ar}-\mathrm{C}_{2} \mathrm{H}_{4}$ gas mixtures with ethylene partial pressures $\left(p_{\mathrm{C}_{2} \mathrm{H}_{4}}\right)$ between $2 \times 10^{-7}$ Torr and $2 \times 10^{-4}$ Torr at substrate temperature $T_{\mathrm{s}}=923 \mathrm{~K}$ and using $p_{\mathrm{C}_{2} \mathrm{H}_{4}}=2 \times 10^{-6}$ Torr at $723 \mathrm{~K} \leq T_{\mathrm{s}} \leq 1123 \mathrm{~K}$. The as-deposited layer microstructure and composition are determined using X-ray diffraction, transmission electron microscopy, and X-ray photoelectron spectroscopy. We find that the layers sputter-deposited at $T_{\mathrm{s}}=923 \mathrm{~K}$ using the lowest $p_{\mathrm{C}_{2} \mathrm{H}_{4}}=2 \times 10^{-7}$ Torr are polycrystalline, close-packed hexagonal structured $\mathrm{Zr}$ : $\mathrm{C}$ solid solutions. At higher $p_{\mathrm{C}_{2} \mathrm{H}_{4}}=2 \times 10^{-6}$ Torr and $2 \times 10^{-5}$ Torr, we obtain films composed of freecarbon (C) and NaCl-structured $\mathrm{ZrC}_{x}, x \leq 1$. The amount of C increases $104 \%$ with ten-fold increase in $p_{\mathrm{C}_{2} \mathrm{H}_{4}}$ from $2 \times 10^{-6}$ Torr to $2 \times 10^{-5}$ Torr. At the highest $p_{\mathrm{C}_{2} \mathrm{H}_{4}}=2 \times 10^{-4}$ Torr, the layers are X-ray amorphous with $\sim 49$ at.\% C. Films grown at $723 \mathrm{~K} \leq T_{\mathrm{s}} \leq 1123 \mathrm{~K}$ using constant $p_{\mathrm{C}_{2} \mathrm{H}_{4}}=2 \times 10^{-6}$ Torr exhibit qualitatively similar microstructures, irrespective of $T_{\mathrm{s}}$, composed of dense columnar $\mathrm{ZrC}_{x}$ grains surrounded by $\mathrm{C}$ and corrugated surfaces. Our results suggest that the compositional and microstructural evolution of $\mathrm{Zr}-\mathrm{C}$ films during reactive 
31 sputter-deposition of $\mathrm{Zr}$ is highly sensitive to ethylene partial pressure, with as little as $0.02 \%$ of 32 the total pressure sufficient at $T_{\mathrm{s}} \geq 723 \mathrm{~K}$ to obtain $\mathrm{ZrC}_{x}$ films.

33 Keywords: transition-metal carbides, reactive magnetron sputtering, $\mathrm{Zr}-\mathrm{C}$ thin films 


\section{Introduction}

Group 4 to 6 transition-metal carbides (TMCs) are highly refractory compounds with

excellent thermomechanical and thermochemical properties due to a mixture of ionic, covalent,

and metallic bonds between the metal cations and carbon anions. Among the TMCs, $\mathrm{ZrC}$

crystallizes in B1 (rock salt) structure ( $\mathrm{Fm} \overline{3} \mathrm{~m}$; space group 225) with a bulk lattice parameter $a_{\mathrm{o}}=$

$0.4693 \mathrm{~nm}$ at room temperature [1]. $\mathrm{ZrC}$ is a hard (> $25 \mathrm{GPa})$, high elastic modulus (> $350 \mathrm{GPa})$,

and high melting point (> $3673 \mathrm{~K}$ ) solid with good thermal $(20.5 \mathrm{~W} / \mathrm{m} . \mathrm{K}$ at $293 \mathrm{~K})$ and electrical

conductivities (2326 S/m at $293 \mathrm{~K}$ ) and excellent resistance to wear, corrosion, and oxidation [2].

$\mathrm{ZrC}$ is used as hard protective coatings on cutting tools [3-7], as structural components in aerospace vehicles, as coating material for nuclear fuel in nuclear reactors [2,3,8-11], and as

control both the thin film composition and the growth rate by appropriate choice of the reactive

gas and its flux [29]. The TMC coatings deposited via this technique typically result in two-phase

mixtures, composed of TMC crystallites and free-carbon (C) [3,24,27], with reactive gas

pressure-dependent TMC and C phase fractions, crystallinity, and mechanical properties

$54 \quad[3,24,26,27,30]$. Recently, Tanaka et al. [31] have demonstrated tunability of Ta-C phase

composition in thin films sputter-deposited with ultra-low amounts of ethylene partial pressures, 
microstructural and compositional evolutions of thin films deposited by sputtering elemental $\mathrm{Zr}$ target using similarly low $p_{\mathrm{C}_{2} \mathrm{H}_{4}}$ between 0.002 and $2 \%$ of the total pressure.

In this paper, we report on the effects of $p_{\mathrm{C}_{2} \mathrm{H}_{4}}$ (between $2 \times 10^{-7}$ Torr and $2 \times 10^{-4}$ Torr) and

60 substrate temperature $\left(723 \mathrm{~K} \leq T_{\mathrm{s}} \leq 1123 \mathrm{~K}\right)$ on the composition and crystallinity of Zr-

$61 \mathrm{C} / \mathrm{MgO}(001)$ thin films sputter-deposited in 10 mTorr $\mathrm{Ar}-\mathrm{C}_{2} \mathrm{H}_{4}$ gas mixtures. (Here, and in the

62 following sections, we use $\mathrm{Zr}-\mathrm{C}$ to refer to both $\mathrm{Zr}$ : $\mathrm{C}$ solid solutions and $\mathrm{ZrC}_{x}, x \leq 1$,

compounds.) Using X-ray diffraction (XRD), transmission electron microscopy (TEM), and X-

64 ray photoelectron spectroscopy (XPS), we characterized the as-deposited layer microstructure and

65 composition. We find that the films sputter-deposited at $T_{\mathrm{s}}=923 \mathrm{~K} \mathrm{using} p_{\mathrm{C}_{2} \mathrm{H}_{4}}=2 \times 10^{-7}$ Torr are polycrystalline with primarily hexagonal close-packed (hcp) $\mathrm{Zr}$ :C solid solutions. At $p_{\mathrm{C}_{2} \mathrm{H}_{4}}=$ $2 \times 10^{-6}$ Torr and $2 \times 10^{-5}$ Torr, the films are composed of a two-phase mixture of B1-structured $\mathrm{ZrC}_{x}$ and $\mathrm{C}$ with an increasing phase fraction of $\mathrm{C}$ with increasing $p_{\mathrm{C}_{2} \mathrm{H}_{4}}$. At $p_{\mathrm{C}_{2} \mathrm{H}_{4}}=2 \times 10^{-4}$ Torr, the film is $\mathrm{X}$-ray amorphous and with a high $\mathrm{C}$ content. The $\mathrm{Zr}-\mathrm{C}$ layers sputter-deposited with $p_{\mathrm{C}_{2} \mathrm{H}_{4}}=2 \times 10^{-6}$ Torr at $T_{\mathrm{s}}$ between $723 \mathrm{~K}$ and $1123 \mathrm{~K}$ are all two-phase mixtures of $\mathrm{B} 1-\mathrm{ZrC}_{x}$ and $\mathrm{C}$ with little changes in the $\mathrm{C}$ content with increasing $T_{\mathrm{s}}$. Our experiments reveal that the carbon content in reactively sputter-deposited $\mathrm{Zr}-\mathrm{C}$ thin films is highly sensitive to the reactive gas pressure.

\section{Experimental details}

All the $\mathrm{Zr}-\mathrm{C}$ films are grown on single-side polished $0.5 \times 2 \times 10 \mathrm{~mm}^{3}$ rectangular strips of $\mathrm{MgO}(001)$ substrates in a custom-designed ultra-high vacuum (UHV, base pressure $<5.3 \times 10^{-9}$ Torr) deposition system following the procedure described in Ref. [32]. Briefly, the $\mathrm{MgO}(001)$ substrates are cut from $0.5 \times 10 \times 10 \mathrm{~mm}^{3}, 99.95 \%$ pure crystals (purchased from MTI), cleaned 
via sonication sequentially in acetone, isopropyl alcohol, and deionized water, and oven-baked in

81 air at $523 \mathrm{~K}$ for one hour. The samples are mounted on a pyrolytic boron nitride heating stage

82 [33], where they are held by Mo clips, transferred to the main chamber, and degassed by

83 resistively heating to and holding at $1273 \mathrm{~K}$ until the chamber pressure is below $6 \times 10^{-9}$ Torr.

84 The sample temperature $T_{\mathrm{s}}$ is then set to the desired value. In our experiments, we estimate that

85 the maximum variation in $T_{\mathrm{s}}$ across the substrate is $\pm 100 \mathrm{~K}$. The magnetron sputter-deposition is

86 carried out using a 3.2-mm-thick $\times 50.8 \mathrm{~mm}$ diameter $\mathrm{Zr}$ target $(99.91 \mathrm{wt} . \%$ pure with $0.08 \mathrm{wt} . \%$

87 Hf from ACI Alloys, Inc.), located at about $30 \mathrm{~cm}$ directly above the substrate. The chamber is

88 first filled with ethylene ( $99.999 \%$ purity) gas up to the desired pressure $p_{\mathrm{C}_{2} \mathrm{H}_{4}}$ between $2 \times 10^{-7}$

89 Torr and $2 \times 10^{-4}$ Torr set using a UHV leak valve. Subsequently, Ar (99.999\% purity) gas is let

90 in and the total pressure is adjusted to 10 mTorr. $\mathrm{Zr}-\mathrm{C}$ thin films are deposited using $\mathrm{Zr}$ target

91 power maintained constant at $50 \mathrm{~W}$ for 30 minutes. The target voltage increases with increasing

$92 p_{\mathrm{C}_{2} \mathrm{H}_{4}}$ from $225 \mathrm{~V}\left(2 \times 10^{-7}\right.$ Torr $)$ to $227 \mathrm{~V}\left(2 \times 10^{-6}\right.$ Torr and $2 \times 10^{-5}$ Torr $)$, and $234 \mathrm{~V}\left(2 \times 10^{-4}\right.$

93 Torr). Prior to deposition, the $\mathrm{Zr}$ target is sputter-cleaned using the same $\mathrm{Ar} / \mathrm{C}_{2} \mathrm{H}_{4}$ composition as

94 that used for the film growth for 2 minutes with the sample rotated out-of-sight from the target.

95 After deposition, the ethylene and Ar gas supplies are shut off and the chamber is evacuated

96 while the sample is passively cooled to room temperature by switching off the current supplied to

97 the substrate heater.

98 XRD 20- $\omega$ data are obtained following the procedure described in Ref. [34] using a Jordan

99 Valley D1 diffractometer with a sealed copper X-ray tube source, a MaxFlux specular mirror to

100 produce a parallel beam, a two bounce channel-cut (2 2 0) Si collimator crystal to select the $\mathrm{Cu}$

$101 \mathrm{~K}_{\alpha 1}$ wavelength $(\lambda=0.154056 \mathrm{~nm})$ for the incident beam, and a two bounce channel-cut (2 20$)$

$102 \mathrm{Si}$ analyzer crystal for the third axis optics. The sample and stage are calibrated with respect to $\omega$, 
$103 \phi$ (out-of-plane rotation perpendicular to $\omega$ ), and $\chi$ (in-plane rotation) about the $\mathrm{MgO}(004)$ peak, $1042 \theta=94.0496^{\circ} .2 \theta-\omega$ scans for $2 \theta$ values between $20^{\circ}$ and $100^{\circ}$ are acquired using double-axis 105 diffraction with a step size of $0.02^{\circ}$ and a dwell time of $1 \mathrm{~s}$.

106 Cross-sectional TEM (XTEM) samples are prepared using $30 \mathrm{kV} \mathrm{Ga}^{+}$ions in an FEI Nova 107600 NanoLab DualBeam ${ }^{\mathrm{TM}}$ scanning electron microscope equipped with a focused ion beam 108 (FIB) source. Prior to milling, the film surface is protected by $\sim 150 \mathrm{~nm}$ and $\sim 1 \mu \mathrm{m}$ thick Pt 109 layers deposited sequentially, first using electron beams to minimize any damage that may incur 110 during the subsequent ion-beam-assisted deposition of the thicker layers. TEM images of the film 111 and the film-substrate interface are acquired in an FEI Titan 80-300 kV scanning TEM (S/TEM) 112 operated at $300 \mathrm{kV}$ for imaging.

113 XPS data are obtained using a Kratos Analytical AXIS Ultra DLD at binding energies 114 between 0 and $1200 \mathrm{eV}$ with a pass energy of $160 \mathrm{eV}$, step size of $1.0 \mathrm{eV}$, and dwell time of $0.1 \mathrm{~s}$. 115 High-resolution $\mathrm{Zr} 3 d$ and C $1 s$ spectra are acquired using a pass energy of $20 \mathrm{eV}$ and a step size 116 of $0.1 \mathrm{eV}$ over the energy ranges $160-215 \mathrm{eV}$ and $264-300 \mathrm{eV}$, respectively, with dwell times

117 of $0.5 \mathrm{~s}$ and $2 \mathrm{~s}$. In order to accurately determine the bulk composition and minimize the 118 contribution to the XPS signal from surface contamination, the XPS data are obtained after $\mathrm{Ar}^{+}$ 119 ion etching of all but one samples for $1 \mathrm{~h}$ and the other sample (grown using $p_{\mathrm{C}_{2} \mathrm{H}_{4}}=2 \times 10^{-7}$ Torr 120 and $T_{\mathrm{s}}=923 \mathrm{~K}$ ) for $2.5 \mathrm{~h}$. The relative concentrations of $\mathrm{Zr}$ and $\mathrm{C}$ in the films are determined 121 from the ratios of the high-resolution $\mathrm{Zr} 3 d$ and $\mathrm{C} 1 s$ spectral peak areas, measured using 122 CasaXPS software and defined with a Shirley background type [35], corrected by their respective 123 relative sensitivity factors, 2.58 and 0.278 . In order to assess the accuracy of our quantification 124 procedure, we acquired both XPS and Rutherford backscattering spectrometry (RBS) data (details 125 below) from the same $\mathrm{ZrC}_{x}$ film (sputter-deposited on $\mathrm{Al}_{2} \mathrm{O}_{3}(0001)$ using a $\mathrm{ZrC}$ target [36]. From 
the XPS measurements, following the procedure described above, we determined the film

127 composition as $\mathrm{C} / \mathrm{Zr}=1.44$, while the $\mathrm{RBS}$ analysis yielded $\mathrm{C} / \mathrm{Zr}=2.04$. The apparent

128 discrepancy in the carbon contents measured using these two techniques could be due to

129 preferential removal of $\mathrm{C}$ from the surface during sputter-etching of the samples prior to XPS

130 measurements coupled with the fact that XPS is a surface-sensitive technique while RBS probes

131 the entire cross-section of the film.

132 RBS-Nuclear Reaction Analysis (RBS-NRA) data, used to determine the film stoichiometry

133 of one sample apart from the set of samples presented in this article, are obtained using 1.2 MeV

134 deuteron beam generated by the nuclear microprobe of CEA Saclay, France. The incident

135 deuteron beam size is $4 \times 3 \mu \mathrm{m}^{2}$. Backscattered particles produced from nuclear reactions are

136 detected with an annular surface barrier particle detector (detection angle $170^{\circ}$ ). C concentrations

137 are measured from the peak of the nuclear reaction ${ }^{12} \mathrm{C}\left(d, p_{0}\right){ }^{13} \mathrm{C}$ and $\mathrm{Zr}$ concentration from that of

138 backscattered deuterons. The film composition is deduced by fitting experimental data with

139 simulated spectra using SIMNRA code [37], which takes into account experimental beam

140 conditions and related cross-sections of scattering and deuteron induced nuclear reactions.

\section{Results and discussion}

Figure 1a shows XRD 2 $\theta-\omega$ scans acquired from $\mathrm{Zr}-\mathrm{C} / \mathrm{MgO}(001)$ samples (open circles)

144 grown at $T_{\mathrm{s}}=923 \mathrm{~K}$ using $\mathrm{Ar} / \mathrm{C}_{2} \mathrm{H}_{4}$ gas mixtures with $p_{\mathrm{C}_{2} \mathrm{H}_{4}}$ between $2 \times 10^{-7}$ Torr and $2 \times 10^{-4}$

145 Torr. In Fig. 1a, the solid line is an experimental XRD 2 $\theta-\omega$ scan of a bare $\mathrm{MgO}(001)$ substrate,

146 provided as a reference. The higher intensity peaks at $2 \theta=42.9^{\circ}$ and $41.0^{\circ}$ labeled with asterisks

147 (*) correspond to 002 reflections of the $\mathrm{MgO}$ single-crystal substrate due to $\mathrm{Cu} \mathrm{K}_{\alpha 1}(\lambda=0.154056$

$148 \mathrm{~nm})$ and unintentional $\mathrm{W} \mathrm{L}_{\alpha}(\lambda=0.147635 \mathrm{~nm})$ radiations from the X-ray source, respectively. 
XRD data obtained from the layers deposited using the lowest $p_{\mathrm{C}_{2} \mathrm{H}_{4}}\left(=2 \times 10^{-7}\right.$ Torr $)$ do not show any peaks due to $\mathrm{B} 1-\mathrm{ZrC}$ but reveal reflections at $2 \theta$ values corresponding to hcp $\mathrm{Zr} 0002$ and $10 \overline{1} 1$. The lattice constants $\left(a_{\mathrm{Zr}}, c_{\mathrm{Zr}}\right)$ determined from the XRD data are $(0.325 \pm 0.003 \mathrm{~nm}$, $0.517 \pm 0.003 \mathrm{~nm})$, which are within the measurement uncertainties the same as $(0.323 \mathrm{~nm}, 0.515$ $\mathrm{nm})$ of pure $\mathrm{Zr}$ [38]. In the same XRD pattern, we also note the presence of seemingly high background intensity at $2 \theta \approx 35^{\circ}$, highlighted by a dotted circle, between the $\mathrm{Zr} 0002$ and $\mathrm{Zr} 10 \overline{1} 1$ peaks. We suggest and provide supporting evidence in the following section that this result is likely due to the formation of hexagonal-structured carbides, e.g., $\mathrm{Zr}_{3} \mathrm{C}_{2}\left(\mathrm{P} 3{ }_{1} 21\right.$, space group 152; $a_{1}=0.306 \mathrm{~nm}$ and $\left.c_{1}=1.491 \mathrm{~nm}\right)$, whose $10 \overline{1} 2$ and 0006 reflections are at $2 \theta=35.9^{\circ}$ and $36.1^{\circ}$, respectively. At higher $p_{\mathrm{C}_{2} \mathrm{H}_{4}}\left(=2 \times 10^{-6}\right.$ Torr and $2 \times 10^{-5}$ Torr $)$, the XRD data reveal peaks corresponding to 002 and 111 reflections of $\mathrm{B} 1$-structured $\mathrm{ZrC}_{x}$. We observe a shift in $\mathrm{ZrC}_{x} 111$ reflection peak position to lower $2 \theta$ values, i.e., 111 interplanar spacing $d_{111}$ increases, with increasing $p_{\mathrm{C}_{2} \mathrm{H}_{4}}$ from $2 \theta=33.12^{\circ}\left(d_{111}=0.270 \mathrm{~nm}\right)$ at $2 \times 10^{-6}$ Torr to $2 \theta=32.84^{\circ}\left(d_{111}=0.273\right.$ $\mathrm{nm}$ ) at $2 \times 10^{-5}$ Torr. (The 002 reflections are too broad to accurately measure any variations in

163 their peak positions and therefore we are unable to determine the existence, if any, of inhomogeneous distortions in the $\mathrm{ZrC}$ lattice.) From the measured $d_{111}$ values at each $p_{\mathrm{C}_{2} \mathrm{H}_{4}}$, we

165 determine $a=0.468 \pm 0.004 \mathrm{~nm}$ at $2 \times 10^{-6}$ Torr and $0.472 \pm 0.004 \mathrm{~nm}$ at $2 \times 10^{-5}$ Torr. The 166 former is, within the measurements uncertainties, the same as $a_{\mathrm{o}}=0.4693 \mathrm{~nm}$ of the bulk 167 stoichiometric $\mathrm{ZrC}$ [1], while the latter is $\sim 0.6 \%$ larger than $a_{\mathrm{o}}$, likely due to distortion of the $\mathrm{ZrC}$ 168 lattice due to increased incorporation of $\mathrm{C}$ in the films $[6,13,26,27]$. Similar shifts in XRD peak 169 positions have been previously observed with increasing carbon contents in sputter-deposited $\mathrm{ZrC}$ 170 [13], HfC [26], and NbC [27] thin films. The XRD scan from the sample grown with the highest $171 p_{\mathrm{C}_{2} \mathrm{H}_{4}}\left(=2 \times 10^{-4}\right.$ Torr $)$ does not show any peaks, suggesting that the film is X-ray amorphous. 
172 Based on the data in Fig. 1a, we identify $p_{\mathrm{C}_{2} \mathrm{H}_{4}}=2 \times 10^{-6}$ Torr as the optimal ethylene partial 173 pressure for the growth of $\mathrm{B} 1-\mathrm{ZrC}$ at $T_{\mathrm{s}}=923 \mathrm{~K}$ in our deposition system.

174 We investigated the effect of $T_{\mathrm{s}}$, another key parameter that can influence the crystallinity of 175 sputter-deposited films [13,39]. Fig. 1b shows XRD data obtained from Zr-C layers sputter176 deposited at $723 \mathrm{~K} \leq T_{\mathrm{s}} \leq 1123 \mathrm{~K}$ using $\mathrm{Ar} / \mathrm{C}_{2} \mathrm{H}_{4}$ gas mixtures with $p_{\mathrm{C}_{2} \mathrm{H}_{4}}=2 \times 10^{-6}$ Torr. At all $177 T_{\mathrm{s}} \leq 1023 \mathrm{~K}$, we observe two sets of peaks corresponding to B1-structured $\mathrm{ZrC}_{x} 111$ reflection at $1782 \theta$ values between $32.92^{\circ}$ and $33.14^{\circ}$, and 002 reflection at around $38.52^{\circ}$. The lattice parameters 179 extracted from the 002 reflection are $\sim 0.5 \%$ smaller compared to $a_{o}$ of stoichiometric $\operatorname{ZrC}[1]$, 180 while those determined from the 111 reflections are $\sim 0.3 \%$ larger (for $2 \theta=32.92^{\circ}$ ) and $\sim 0.3 \%$ smaller (for $2 \theta=33.14^{\circ}$ ) than $a_{o}$. The peaks are however too broad and weak in intensity to 182 accurately determine the temperature-dependent variations, if any, in the carbon content $x$, grain size, and strain. Interestingly, the XRD data obtained from the $\mathrm{ZrC}_{x}$ film grown at the highest $T_{\mathrm{s}}=$ $1841123 \mathrm{~K}$ showed only one peak corresponding to 002 reflection, indicating that 002 texture is 185 preferred at higher $T_{\mathrm{s}}$. These results suggest that, in our experiments, 111 texture is promoted in 186 sputter-deposited $\mathrm{ZrC}_{x}$ at lower $T_{\mathrm{s}}$, a likely consequence of kinetic limitations inherent to the 187 deposition process. Similar $T_{\mathrm{s}}$-dependent 111 texture evolution has been reported in a variety of 188 sputter-deposited TMC thin films [13,28,39-41].

189 We now present the microstructures of $\mathrm{Zr}-\mathrm{C}$ layers sputter-deposited as a function of $p_{\mathrm{C}_{2} \mathrm{H}_{4}}$ 190 and $T_{\mathrm{s}}$. Figs. 2a-d are typical XTEM images obtained from the $\mathrm{Zr}-\mathrm{C}$ thin films grown at $T_{\mathrm{s}}=923$ $191 \mathrm{~K}$ using $p_{\mathrm{C}_{2} \mathrm{H}_{4}}=$ a) $2 \times 10^{-7}$ Torr, b) $2 \times 10^{-6}$ Torr, c) $2 \times 10^{-5}$ Torr, and d) $2 \times 10^{-4}$ Torr. We find 192 that the film thickness increases with increasing $p_{\mathrm{C}_{2} \mathrm{H}_{4}}$ from $87 \pm 4 \mathrm{~nm}$ at $p_{\mathrm{C}_{2} \mathrm{H}_{4}}=2 \times 10^{-7}$ Torr to $193245 \pm 20 \mathrm{~nm}$ at $p_{\mathrm{C}_{2} \mathrm{H}_{4}}=2 \times 10^{-4}$ Torr. (This is in contrast with the results reported in Ref. [13], 
194 where the deposition rate decreases with increasing reactive gas (methane) partial pressure.) We 195 attribute this result to the increase in the carbon content (supporting evidence provided in the 196 following section) within the films with increasing $p_{\mathrm{C}_{2} \mathrm{H}_{4}}$ during sputter-deposition. The TEM 197 images of $\mathrm{Zr}-\mathrm{C}$ sample deposited using $p_{\mathrm{C}_{2} \mathrm{H}_{4}}=2 \times 10^{-7}$ Torr reveal that the film is dense with 198 smooth surface and compositionally-abrupt film-substrate interface (see Fig. 2a); these results are 199 in striking contrast with the interfacial reactions observed during sputter-deposition of pure $\mathrm{Zr}$ 200 films on $\mathrm{Al}_{2} \mathrm{O}_{3}(0001)$ [33]. Lattice-resolved TEM image (for example, Fig. 2a') and 201 corresponding Fourier transform (FT) (inset in Fig. 2a') show that the Zr-C layers deposited with 202 the lowest $p_{\mathrm{C}_{2} \mathrm{H}_{4}}=2 \times 10^{-7}$ Torr are crystalline and that the layer is primarily composed of hcp203 structured $\mathrm{Zr}$. We have also observed additional reflections that we attribute to trigonal- $\mathrm{Zr}_{3} \mathrm{C}_{2}$ $204000 \overline{3}$, the presence of which could explain the observed high background XRD intensity at $2 \theta \approx$ $20535^{\circ}$ in Fig. 1a. This result suggests the coexistence of hcp- $\mathrm{Zr}$ and trigonal $\mathrm{Zr}_{3} \mathrm{C}_{2}$. Increasing $p_{\mathrm{C}_{2} \mathrm{H}_{4}}$ 206 to $2 \times 10^{-6}$ Torr and $2 \times 10^{-5}$ Torr leads to porous films with dendritic columns and facetted 207 surfaces (Figs. 2b and c). The corresponding higher resolution XTEM images in Figs. 2b' and c' 208 reveal regions with diffraction contrast indicative of crystallinity; surrounding regions without 209 such contrast are likely composed of amorphous C. FTs in Figs. 2b' and c' reveal reflections 210 corresponding to B1-structured 002 and 111 grains in the films, consistent with the XRD results.

211 FTs (not shown here) of the XTEM images acquired from the regions near the film-substrate 212 interfaces in these two samples reveal two sets of identical reflections, indicative of cube-on-cube 213 epitaxial growth of 002 -oriented $\mathrm{ZrC}$ layers on the $\mathrm{MgO}(001)$ substrate. At the highest $p_{\mathrm{C}_{2} \mathrm{H}_{4}}=2$ $214 \times 10^{-4}$ Torr used in our experiments, the layers appear to be dense (see Fig. 2d). The XTEM 215 image in Fig. 2d' lacks any diffraction contrast and the corresponding FT shows a broad diffuse 216 ring, commonly associated with amorphous samples. These observations suggest that the $\mathrm{Zr}$-C 
217 films deposited using $2 \times 10^{-4}$ Torr ethylene are amorphous and are consistent with the XRD data 218 (Fig. 1a).

219 Figs. 3a-d and 3a'-d' are series of low-magnification and higher-resolution XTEM images, 220 respectively, obtained from near the substrate-film interfaces in the $\mathrm{ZrC}_{x} / \mathrm{MgO}(001)$ samples 221 grown using $p_{\mathrm{C}_{2} \mathrm{H}_{4}}=2 \times 10^{-6}$ Torr at different $T_{\mathrm{s}}$. All the TEM images reveal fully dense layers 222 with columnar grains and corrugated surfaces, indicating that the growth morphologies and 223 microstructures are qualitatively similar in all the samples grown at different $T_{\mathrm{s}}$. XTEM images 224 (not shown here) obtained along the growth direction also reveal the presence of amorphous regions throughout the films. These results are qualitatively similar to those reported in previous 226 studies [3]. Diffraction spots corresponding to both $\mathrm{ZrC}_{x} 002$ and 111 reflections are observed in 227 the FTs in Figs. 3a'-c', indicating that the films are polycrystalline. The FT in Fig. 3d' shows only 228002 reflections due to $\mathrm{B} 1-\mathrm{ZrC}_{x}$, consistent with the XRD data in Fig. 1b. From the $\mathrm{ZrC} 002$ reflections, we extract $a$ values $(=0.47 \pm 0.01 \mathrm{~nm}), \sim 0.5 \%$ smaller compared to $a_{o}$, and are 230 consistent with the value determined from the XRD data. High-resolution TEM images along 231 with their corresponding FTs (not shown here) of all samples show the presence of only 002232 oriented $\mathrm{ZrC}$ grains at the interface with a cube-on-cube relation with respect to the $\mathrm{MgO}(001)$ 233 substrate, indicative of heteroepitaxial growth during the early stages of deposition.

234 In order to quantify the free and the bonded carbon contents in $\mathrm{ZrC}_{x}$ in the films, we used 235 XPS. Fig. 4a shows representative high-resolution $\mathrm{C} 1 s$ and $\mathrm{Zr} 3 d$ XPS data acquired from the 236 bulk of $\mathrm{Zr}-\mathrm{C}$ samples grown using different $p_{\mathrm{C}_{2} \mathrm{H}_{4}}$. Within these spectra, we identify peaks 237 associated with carbon at binding energies: $284.0 \sim 284.2 \mathrm{eV}$ as $\mathrm{C}-\mathrm{C}$ bonds in free-carbon; 281.2 $238 \sim 282 \mathrm{eV}$ as $\mathrm{C}-\mathrm{Zr}$ bonds; and $282 \sim 284 \mathrm{eV}$ as $\mathrm{C}-\mathrm{Zr}{ }^{*}$ bonds $[3,5,42,43]$. The XPS peak due to C$239 \mathrm{C}$ bond in carbides is often attributed to the presence of disordered, $s p^{2}$ (graphite), and/or $s p^{3}$ 
240 (diamond) hybridized carbon, whose exact contributions to the XPS signal are not resolvable in 241 our measurements [6,44]. The peaks observed at binding energies between 178.1 and $180.5 \mathrm{eV}$ 242 correspond to $\mathrm{Zr} 3 d_{5 / 2}$ and $\mathrm{Zr} 3 d_{3 / 2}$, respectively. We find that the $\mathrm{Zr}$ peaks are better defined at 243 lower $p_{\mathrm{C}_{2} \mathrm{H}_{4}}$ than at higher values, presumably due to the decrease in free-C content. With 244 increasing $p_{\mathrm{C}_{2} \mathrm{H}_{4}}$, we observe a shift (compared to the dashed vertical lines in the plot, which 245 correspond to binding energies in stoichiometric $\mathrm{ZrC}$ ) in the $\mathrm{C}-\mathrm{Zr}$ and $\mathrm{Zr} 3 d$ peak positions to 246 higher binding energies. Based on the increase in C-C, and concomitant decrease in the $\mathrm{C}-\mathrm{Zr}$, 247 peak intensities with increasing $p_{\mathrm{C}_{2} \mathrm{H}_{4}}$, we suggest that the observed peak shifts are due to the 248 increase in free-C content in the films.

249 From the measurements of the $\mathrm{Zr} 3 d, \mathrm{C}-\mathrm{C}, \mathrm{C}-\mathrm{Zr}$, and $\mathrm{C}-\mathrm{Zr}$ * peak areas from Fig. 4a, we 250 quantify the concentrations of total carbon, free-C, and bonded-carbon $x$ in $\mathrm{ZrC}_{x}$, plotted as 251 magenta, black, and green curves, respectively, as a function of $p_{\mathrm{C}_{2} \mathrm{H}_{4}}$ in Fig. 4b. The label free-C 252 in the plot refers to the elemental carbon that is not bonded to $\mathrm{Zr}$ and corresponds to C-C peaks in 253 Fig. 4a. We find that the amount of total $\mathrm{C}$ and free-C increase while the fraction of carbon 254 bonded to $\mathrm{Zr}$, i.e. the carbide phase, decreases with increasing $p_{\mathrm{C}_{2} \mathrm{H}_{4}}$ during sputter-deposition. 255 These results are consistent with the observation of increasing fraction of amorphous phase with 256 increasing $p_{\mathrm{C}_{2} \mathrm{H}_{4}}$ in the TEM images in Fig. 2 and are commonly observed in sputter-deposited 257 Zr-C films [3]. Interestingly, the fraction of free-C relative to the amount of carbon in the carbide 258 phase is higher in our films than in the films deposited using three orders of magnitude higher 259 reactive gas (methane) partial pressure [3]. Possible reasons for this behavior include: differences 260 in the rates of dissociative chemisorption of carbon due to precursor composition (relatively more 261 stable methane with one $\mathrm{C}$ atom/molecule vs. ethylene with two $\mathrm{C}$ atoms/molecule), $\mathrm{Zr}$ 262 deposition rates, $T_{\mathrm{s}}$, total gas pressure, plasma characteristics, and residual gas composition and 
concentration. Among all these samples, based on the XPS data, we note that the films deposited 264 using $p_{\mathrm{C}_{2} \mathrm{H}_{4}}=2 \times 10^{-6}$ Torr yield the highest fraction of $\mathrm{Zr}$ - $\mathrm{C}$ phase with the least amount of free-

265 C. In the following section, we present the effect of $T_{\mathrm{s}}$ on the composition of $\mathrm{Zr}-\mathrm{C}$ films deposited 266 with $p_{\mathrm{C}_{2} \mathrm{H}_{4}}=2 \times 10^{-6}$ Torr.

Fig. 4c shows representative C $1 s$ and $\mathrm{Zr} 3 d$ spectra obtained from the $\mathrm{Zr}-\mathrm{C}$ samples grown at different $T_{\mathrm{s}}$ using $p_{\mathrm{C}_{2} \mathrm{H}_{4}}=2 \times 10^{-6}$ Torr. From the spectra, we identify the two characteristic $\mathrm{Zr}$ $3 d_{5 / 2}$ and $3 d_{3 / 2}$ peaks. In the $\mathrm{C} 1 s$ spectra, we observe one high intensity peak at $\sim 281 \mathrm{eV}$, which we attribute to $\mathrm{C}-\mathrm{Zr}$ bonds, and one relatively broader peak around $284 \mathrm{eV}$ due to $\mathrm{C}-\mathrm{C}$ bonds.

271 With increasing $T_{\mathrm{s}}$, we observe shifts $(\sim 0.3 \mathrm{eV})$ in both the $\mathrm{Zr} 3 d$ and $\mathrm{C}-\mathrm{Zr}$ peaks to higher 272 binding energies, suggestive of stronger bonding presumably due to decrease in the C-content 273 within the carbide; the magnitude of shift is more pronounced at higher $T_{\mathrm{s}}(\geq 923 \mathrm{~K})$. In all the samples grown at different $T_{\mathrm{s}}, \mathrm{C}-\mathrm{C}$ peaks are broad, shallow, and changes (if any) in the peak positions are not detectable. The $T_{\mathrm{s}}$-dependent changes in total $\mathrm{C}$, free-C, and bonded-carbon concentrations are plotted in Fig. 4d. We find that the amounts of total $\mathrm{C}$ (magenta curve) and free-C (black curve) increase marginally with increasing $T_{\mathrm{s}}$, indicating that substrate temperatures over $723 \mathrm{~K}$ have little influence on the total $\mathrm{C}$ and free- $\mathrm{C}$ contents in the $\mathrm{Zr}$ - $\mathrm{C}$ films sputterdeposited using $p_{\mathrm{C}_{2} \mathrm{H}_{4}}=2 \times 10^{-6}$ Torr. (These results are opposite to those reported for $\mathrm{Zr}$ - $\mathrm{C}$ films sputter-deposited using methane gas [13], which as mentioned earlier could be not only due to the use of ethylene vs. methane but also system-specific deposition parameters.) Based on these results, we suggest that during reactive sputter-deposition of $\mathrm{Zr}$ using low ethylene partial pressures, such as $p_{\mathrm{C}_{2} \mathrm{H}_{4}}=2 \times 10^{-6}$ Torr, incorporation of $\mathrm{C}$ from $\mathrm{C}_{2} \mathrm{H}_{4}$ into the growing films occurs readily at all $T_{\mathrm{s}} \geq 723 \mathrm{~K}$. 


\section{Conclusions}

This report presents the effects of ethylene partial pressure $\left(p_{\mathrm{C}_{2} \mathrm{H}_{4}}\right)$ and substrate temperature

$\left(T_{\mathrm{s}}\right)$ on the microstructural and compositional evolution of reactively sputter-deposited $\mathrm{Zr}-\mathrm{C}$ thin

films on $\mathrm{MgO}(001)$ substrates using ultra-high vacuum dc magnetron sputtering of $\mathrm{Zr}$ target in

$290 \mathrm{Ar} / \mathrm{C}_{2} \mathrm{H}_{4}$ gas mixtures with fairly low $p_{\mathrm{C}_{2} \mathrm{H}_{4}} \leq 2 \%$ of the total pressure. We find that all the $\mathrm{Zr}-\mathrm{C}$

291 films, irrespective of the $p_{\mathrm{C}_{2} \mathrm{H}_{4}}$ and $T_{\mathrm{s}}$, are polycrystalline two-phase mixtures composed of

292 hexagonal close-packed $\mathrm{Zr}: \mathrm{C}$ solid solutions (at ultra-low $p_{\mathrm{C}_{2} \mathrm{H}_{4}}=0.002 \%$ ) or B1-ZrC (at higher

$\left.293 \quad p_{\mathrm{C}_{2} \mathrm{H}_{4}}\right)$ and free-C. The amount of free-C incorporated into the films depends sensitively on $p_{\mathrm{C}_{2} \mathrm{H}_{4}}$

294 at $T_{\mathrm{s}}=923 \mathrm{~K}$. Increasing the $T_{\mathrm{s}}$ above $723 \mathrm{~K}$ (with $p_{\mathrm{C}_{2} \mathrm{H}_{4}}=2 \times 10^{-6}$ Torr) has little effect on the

295 carbon incorporation rate. Our results indicate that relatively small amount of ethylene gas

296 (0.02\% of the total pressure in our experiments) is sufficient to deposit two-phase mixtures of

$297 \mathrm{ZrC}$ and free-carbon. Given that pure, single-phase carbide films are often desirable, we suggest

298 that reactive sputter-deposition of $\mathrm{ZrC}$ (and other TMC) films is probably best carried out using

299 ultra-low partial pressures of carbon containing precursors; the exact pressure however depends

300 on the deposition system, substrate temperature, deposition rate, and the precursor.

302 Acknowledgements

303 We gratefully acknowledge support from the Air Force Office of Scientific Research (AFOSR, 304 Dr. Ali Sayir) under Grant \# FA9550-14-1-0106 and \# FA9550-18-1-0050. We thank the Office 305 of Naval Research (Dr. Chagaan Baatar) for the funds received under Grant \#N00014-12-1-0518 306 used to build the UHV deposition system. KT is supported by the Japanese Student Service 307 Organization (L16111111026) and the UCLA department of materials science and engineering 308 for his doctoral study in the United States. AA is supported by the National Science Foundation 
309 (NSF CMMI) grant \#1563427 (Dr. Kara Peters). We thank Mr. Noah Bodzin and the

310 Nanoelectronics Research Facility in the UCLA Henry Samueli School of Engineering for

311 assistance with focused ion beam milling and acknowledge the use of instruments at the Electron

312 Imaging Center for NanoMachines supported by NIH (1S10RR23057) and the California

313 NanoSystems Institute at UCLA. 


\section{References}

315 [1] M. Morris, E.H. Evans, H.S. Parker, W. Wong-Ng, D.M. Gladhill, C.R. Hubbard, Standard http://archive.org/details/standardxraydiff2521morr (accessed March 18, 2019).

[2] H.O. Pierson, Handbook of Refractory Carbides and Nitrides: Properties, Characteristics, Processing and Applications, Elsevier Science, New Jersey, USA, 1996.

[3] Q.N. Meng, M. Wen, F. Mao, N. Nedfors, U. Jansson, W.T. Zheng, Deposition and characterization of reactive magnetron sputtered zirconium carbide films, Surface and Coatings Technology. 232 (2013) 876-883. https://doi.org/10.1016/j.surfcoat.2013.06.116.

[4] S. Norgren, J. García, A. Blomqvist, L. Yin, Trends in the P/M hard metal industry, International Journal of Refractory Metals and Hard Materials. 48 (2015) 31-45. https://doi.org/10.1016/j.ijrmhm.2014.07.007.

[5] M. Andersson, S. Urbonaite, E. Lewin, U. Jansson, Magnetron sputtering of $\mathrm{Zr}-\mathrm{Si}-\mathrm{C}$ thin films, Thin Solid Films. 520 (2012) 6375-6381. https://doi.org/10.1016/j.tsf.2012.06.044.

[6] L.E. Toth, Transition metal carbides and nitrides, Academic Press, 1971.

[7] J. Balko, T. Csanádi, R. Sedlák, M. Vojtko, A. KovalLíková, K. Koval, P. Wyzga, A. Naughton-Duszová, Nanoindentation and tribology of $\mathrm{VC}, \mathrm{NbC}$ and $\mathrm{ZrC}$ refractory carbides, Journal of the European Ceramic Society. 37 (2017) 4371-4377. https://doi.org/10.1016/j.jeurceramsoc.2017.04.064.

[8] F. Monteverde, A. Bellosi, L. Scatteia, Processing and properties of ultra-high temperature ceramics for space applications, Materials Science and Engineering: A. 485 (2008) 415421. https://doi.org/10.1016/j.msea.2007.08.054.

[9] K. Minato, T. Ogawa, K. Fukuda, H. Nabielek, H. Sekino, Y. Nozawa, I. Takahashi, Fission product release from $\mathrm{ZrC}$-coated fuel particles during postirradiation heating at $1600^{\circ} \mathrm{C}$, Journal of Nuclear Materials. 224 (1995) 85-92. https://doi.org/10.1016/00223115(95)00032-1.

[10] S. Ueta, J. Aihara, A. Yasuda, H. Ishibashi, T. Takayama, K. Sawa, Fabrication of uniform $\mathrm{ZrC}$ coating layer for the coated fuel particle of the very high temperature reactor, Journal of Nuclear Materials. 376 (2008) 146-151. https://doi.org/10.1016/j.jnucmat.2008.02.068.

[11] Y. Katoh, G. Vasudevamurthy, T. Nozawa, L.L. Snead, Properties of zirconium carbide for nuclear fuel applications, Journal of Nuclear Materials. 441 (2013) 718-742. https://doi.org/10.1016/j.jnucmat.2013.05.037.

[12] W.A. Mackie, P.R. Davis, Single-crystal zirconium carbide as a high-temperature thermionic cathode material, IEEE Transactions on Electron Devices. 36 (1989) 220-224. https://doi.org/10.1109/16.21209.

[13] J. Brückner, T. Mäntylä, Reactive magnetron sputtering of zirconium carbide films using Ar-CH4 gas mixtures, Surface and Coatings Technology. 59 (1993) 166-170. https://doi.org/10.1016/0257-8972(93)90077-2.

[14] J. Xu, S. Jiang, Y. Wang, S. Shang, D. Miao, R. Guo, Photo-thermal conversion and thermal insulation properties of $\mathrm{ZrC}$ coated polyester fabric, Fibers Polym. 18 (2017) 1938-1944. https://doi.org/10.1007/s12221-017-1237-z.

[15] X.-H. Gao, H.-X. Guo, T.-H. Zhou, G. Liu, Optical properties and failure analysis of ZrCZrOx ceramic based spectrally selective solar absorbers deposited at a high substrate temperature, Solar Energy Materials and Solar Cells. 176 (2018) 93-99. https://doi.org/10.1016/j.solmat.2017.11.018. 
[16] M. Balden, B.T. Cieciwa, I. Quintana, E. de Juan Pardo, F. Koch, M. Sikora, B. Dubiel, Metal-doped carbon films obtained by magnetron sputtering, Surface and Coatings Technology. 200 (2005) 413-417. https://doi.org/10.1016/j.surfcoat.2005.02.218.

[17] M. Dollé, D. Gosset, C. Bogicevic, F. Karolak, D. Simeone, G. Baldinozzi, Synthesis of nanosized zirconium carbide by a sol-gel route, Journal of the European Ceramic Society. 27 (2007) 2061-2067. https://doi.org/10.1016/j.jeurceramsoc.2006.06.005.

[18] K. Minato, T. Ogawa, T. Koya, H. Sekino, T. Tomita, Retention of fission product caesium in $\mathrm{ZrC}$-coated fuel particles for high-temperature gas-cooled reactors, Journal of Nuclear Materials. 279 (2000) 181-188. https://doi.org/10.1016/S0022-3115(00)00015-5.

[19] G.H. Reynolds, Chemical vapor deposition of $\mathrm{ZrC}$ on pyrocarbon-coated fuel particles, J. Nucl. Mater., v. 50, No. 2, Pp. 215-216. (1974). https://doi.org/10.1016/00223115(74)90158-5.

[20] Y.S. Won, V.G. Varanasi, O. Kryliouk, T.J. Anderson, L. McElwee-White, R.J. Perez, Equilibrium analysis of zirconium carbide CVD growth, Journal of Crystal Growth. 307 (2007) 302-308. https://doi.org/10.1016/j.jcrysgro.2007.05.039.

[21] V. Craciun, J. Woo, D. Craciun, R.K. Singh, Epitaxial ZrC thin films grown by pulsed laser deposition, Applied Surface Science. 252 (2006) 4615-4618. https://doi.org/10.1016/j.apsusc.2005.07.139.

[22] L. D'Alessio, A. Santagata, R. Teghil, M. Zaccagnino, I. Zaccardo, V. Marotta, D. Ferro, G. De Maria, Zirconium carbide thin films deposited by pulsed laser ablation, Applied Surface Science. 168 (2000) 284-287. https://doi.org/10.1016/S0169-4332(00)00625-5.

[23] E. Portolan, C.L.G. Amorim, G.V. Soares, C. Aguzzoli, C.A. Perottoni, I.J.R. Baumvol, C.A. Figueroa, Carbon occupancy of interstitial sites in vanadium carbide films deposited by direct current reactive magnetron sputtering, Thin Solid Films. 517 (2009) 6493-6496. https://doi.org/10.1016/j.tsf.2009.03.202.

[24] X. Wu, G. Li, Y. Chen, G. Li, Microstructure and mechanical properties of vanadium carbide coatings synthesized by reactive magnetron sputtering, International Journal of Refractory Metals and Hard Materials. 27 (2009) 611-614. https://doi.org/10.1016/j.jirmhm.2008.09.014.

[25] A.Z. Ait Djafer, N. Saoula, N. Madaoui, A. Zerizer, Deposition and characterization of titanium carbide thin films by magnetron sputtering using Ti and TiC targets, Applied Surface Science. 312 (2014) 57-62. https://doi.org/10.1016/j.apsusc.2014.05.084.

[26] G. Li, G. Li, Microstructure and mechanical properties of hafnium carbide coatings synthesized by reactive magnetron sputtering, J Coat Technol Res. 7 (2010) 403-407. https://doi.org/10.1007/s11998-009-9225-x.

[27] K. Zhang, M. Wen, G. Cheng, X. Li, Q.N. Meng, J.S. Lian, W.T. Zheng, Reactive magnetron sputtering deposition and characterization of niobium carbide films, Vacuum. 99 (2014) 233-241. https://doi.org/10.1016/j.vacuum.2013.06.012.

[28] S.S. Kumar, A. Sharma, G.M. Rao, S. Suwas, Investigations on the effect of substrate temperature on the properties of reactively sputtered zirconium carbide thin films, Journal of Alloys and Compounds. 695 (2017) 1020-1028. https://doi.org/10.1016/j.jallcom.2016.10.225.

[29] N.C. Zoita, V. Braic, M. Danila, A.M. Vlaicu, C. Logofatu, C.E.A. Grigorescu, M. Braic, Influence of film thickness on the morphological and electrical properties of epitaxial TiC films deposited by reactive magnetron sputtering on $\mathrm{MgO}$ substrates, Journal of Crystal Growth. 389 (2014) 92-98. https://doi.org/10.1016/j.jcrysgro.2013.11.076. 
405

406

407

408

409

410

411

412

413

414

415

416

417

418

419

420

421

422

423

424

425

426

427

428

429

430

431

432

433

434

435

436

437

438

439

440

441

442

443

444

445

446

447

448

449

450

[30] D.D. Kumar, N. Kumar, S. Kalaiselvam, R. Radhika, S. Dash, A.K. Tyagi, R. Jayavel, Reactive magnetron sputtered wear resistant multilayer transition metal carbide coatings: microstructure and tribo-mechanical properties, RSC Adv. 5 (2015) 81790-81801. https://doi.org/10.1039/C5RA16465F.

[31] K. Tanaka, A. Aleman, M.E. Liao, Y. Wang, M.S. Goorsky, S. Kodambaka, Effects of ultralow ethylene partial pressure on microstructure and composition of reactively sputterdeposited Ta-C thin films, Thin Solid Films. 688 (2019) 137440. https://doi.org/10.1016/j.tsf.2019.137440.

[32] J. Fankhauser, M. Sato, D. Yu, A. Ebnonnasir, M. Kobashi, M.S. Goorsky, S. Kodambaka, Growth and characterization of epitaxial $\mathrm{Zr}(0001)$ thin films on A12O3(0001), Journal of Vacuum Science \& Technology A. 34 (2016) 050606. https://doi.org/10.1116/1.4961452.

[33] K. Tanaka, J. Fankhauser, H. Zaid, A. Aleman, M. Sato, D. Yu, A. Ebnonnasir, C. Li, M. Kobashi, M.S. Goorsky, S. Kodambaka, Kinetics of Zr-Al intermetallic compound formation during ultra-high vacuum magnetron sputter-deposition of $\mathrm{Zr} / \mathrm{Al} 2 \mathrm{O} 3(0001)$ thin films, Acta Materialia. 152 (2018) 34-40. https://doi.org/10.1016/j.actamat.2018.04.018.

[34] A. Aleman, C. Li, H. Zaid, H. Kindlund, J. Fankhauser, S.V. Prikhodko, M.S. Goorsky, S. Kodambaka, Ultrahigh vacuum dc magnetron sputter-deposition of epitaxial $\mathrm{Pd}(111) / \mathrm{Al} 2 \mathrm{O} 3(0001)$ thin films, Journal of Vacuum Science \& Technology A. 36 (2018) 030602. https://doi.org/10.1116/1.5021609.

[35] N. Fairley, A. Carrick, Casa XPS User's Manual, (2001).

[36] J.P. Fankhauser, Growth and Characterization of $\mathrm{Zr}$ and $\mathrm{ZrC}$ Thin Films on Al2O3(0001), UCLA, 2016. https://escholarship.org/uc/item/6db4489v (accessed February 15, 2020).

[37] M. Mayer, SIMNRA, a simulation program for the analysis of NRA, RBS and ERDA, AIP Conference Proceedings. 475 (1999) 541-544. https://doi.org/10.1063/1.59188.

[38] A.I. Kolesnikov, A.M. Balagurov, I.O. Bashkin, A.V. Belushkin, E.G. Ponyatovsky, M. Prager, Neutron scattering studies of ordered gamma -ZrD, J. Phys.: Condens. Matter. 6 (1994) 8977-8988. https://doi.org/10.1088/0953-8984/6/43/004.

[39] C. Aguzzoli, C.A. Figueroa, G.V. Soares, I.J.R. Baumvol, Physicochemical and structural characteristics of TiC and VC thin films deposited by DC reactive magnetron sputtering, J Mater Sci. 45 (2010) 4994-5001. https://doi.org/10.1007/s10853-010-4364-0.

[40] H. Colder, R. Rizk, M. Morales, P. Marie, J. Vicens, I. Vickridge, Influence of substrate temperature on growth of nanocrystalline silicon carbide by reactive magnetron sputtering, Journal of Applied Physics. 98 (2005) 024313. https://doi.org/10.1063/1.1985975.

[41] C.-S. Chen, C.-P. Liu, C.-Y.A. Tsao, Influence of growth temperature on microstructure and mechanical properties of nanocrystalline zirconium carbide films, Thin Solid Films. 479 (2005) 130-136. https://doi.org/10.1016/j.tsf.2004.11.196.

[42] A. Escudeiro, N.M. Figueiredo, T. Polcar, A. Cavaleiro, Structural and mechanical properties of nanocrystalline $\mathrm{Zr}$ co-sputtered a-C(:H) amorphous films, Applied Surface Science. 325 (2015) 64-72. https://doi.org/10.1016/j.apsusc.2014.11.015.

[43] U. Jansson, E. Lewin, Sputter deposition of transition-metal carbide films - A critical review from a chemical perspective, Thin Solid Films. 536 (2013) 1-24. https://doi.org/10.1016/j.tsf.2013.02.019.

[44] R. Blume, D. Rosenthal, J.-P. Tessonnier, H. Li, A. Knop-Gericke, R. Schlögl, Characterizing Graphitic Carbon with X-ray Photoelectron Spectroscopy: A Step-by-Step Approach, ChemCatChem. 7 (2015) 2871-2881. https://doi.org/10.1002/cctc.201500344. 


\section{List of Figures}

452

453 Fig. 1. 20- $\omega$ X-ray diffraction (XRD) data obtained from $\mathrm{Zr}-\mathrm{C} / \mathrm{MgO}(001)$ samples sputter-

454 deposited in 10 mTorr $\mathrm{Ar} / \mathrm{C}_{2} \mathrm{H}_{4}$ gas mixtures at (a) $T_{\mathrm{s}}=923 \mathrm{~K}$ with $2 \times 10^{-7}$ Torr $\leq p_{\mathrm{C}_{2} \mathrm{H}_{4}} \leq 2 \times$

$45510^{-4}$ Torr and (b) $723 \mathrm{~K} \leq T_{\mathrm{s}} \leq 1123 \mathrm{~K}$ using $p_{\mathrm{C}_{2} \mathrm{H}_{4}}=2 \times 10^{-6}$ Torr. An XRD scan of $\mathrm{MgO}(001)$

456 substrate (solid line) is plotted as a reference. The peaks labeled with * denote $\mathrm{MgO} 002$

457 reflections due to $\mathrm{Cu} \mathrm{K} \alpha$ at $2 \theta=42.9^{\circ}$ and $\mathrm{W} \mathrm{L} \alpha$ at $2 \theta=40.94^{\circ}$. The vertical dashed lines

458 identify the 111 and 002 reflections in stoichiometric $\mathrm{B} 1-\mathrm{ZrC}$ and 0002 and $10 \overline{1} 1$ reflections in

459 hcp-Zr. The dotted circle highlights the high background intensity at $2 \theta \sim 35^{\circ}$.

460

461 Fig. 2. Typical bright-field cross-sectional transmission electron microscopy (XTEM) images of

$462 \mathrm{Zr}-\mathrm{C} / \mathrm{MgO}(001)$ samples grown at $T_{\mathrm{s}}=923 \mathrm{~K}$ with $p_{\mathrm{C}_{2} \mathrm{H}_{4}}=$ (a) $2 \times 10^{-7}$ Torr, (b) $2 \times 10^{-6}$ Torr, (c)

$4632 \times 10^{-5}$ Torr, and (d) $2 \times 10^{-4}$ Torr. (a'-d') Higher resolution XTEM images of the samples in (a-

$464 \mathrm{~d}$ ), respectively. The insets are the Fourier transforms (FTs) of the images in a'-d'. Cyan, purple,

465 red, and green circles highlight $\mathrm{Zr} 0002, \mathrm{Zr}_{3} \mathrm{C}_{2} 000 \overline{3}, \mathrm{ZrC} \mathrm{002}$, and $\mathrm{ZrC} 111$ reflections,

466 respectively. The absence of any spots in the Fig. 2d' FT implies that the region within the field of

467 view is likely amorphous.

468

469 Fig. 3. Bright-field XTEM images of $\mathrm{Zr}-\mathrm{C} / \mathrm{MgO}(001)$ samples sputter-deposited using $p_{\mathrm{C}_{2} \mathrm{H}_{4}}=2$

$470 \times 10^{-6}$ Torr at $T_{\mathrm{s}}=($ a) $723 \mathrm{~K}$, (b) $823 \mathrm{~K}$, (c) $1023 \mathrm{~K}$, and (d) $1123 \mathrm{~K}$. All the samples appear

471 dense with columnar microstructures and smoother surfaces. (a'-d') Representative higher-

472 resolution XTEM images with corresponding FTs as insets of the samples in (a-d), respectively. 
473 All the TEM images show crystalline and amorphous regions. $\mathrm{ZrC} 002$ and 111 reflections are 474 highlighted using red and green circles in the FTs, respectively.

475 Fig. 4. (a) X-ray photoelectron spectroscopy (XPS) data acquired around Zr 3d (175-190 eV)

476 and $\mathrm{C} 1 s(279-288 \mathrm{eV})$ from sputter-etched $\mathrm{Zr}-\mathrm{C}$ samples deposited as a function of $p_{\mathrm{C}_{2} \mathrm{H}_{4}} \cdot$ (b)

477 Total, free, and bonded carbon concentrations extracted from the XPS data plotted as a function 478 of $p_{\mathrm{C}_{2} \mathrm{H}_{4}}$. (c) XPS data of sputter-etched $\mathrm{Zr}-\mathrm{C}$ samples deposited as a function of $T_{\mathrm{s}}$. (d) Plot of 479 total, free, and bonded carbon concentrations vs. $T_{\mathrm{s}}$. In both (a) and (c), the dashed vertical lines 480 correspond to binding energies in stoichiometric $\mathrm{ZrC}$; black, purple, and light magenta curves 481 correspond to $\mathrm{C}-\mathrm{C}, \mathrm{C}-\mathrm{Zr}$, and $\mathrm{C}-\mathrm{Zr}$ * components, respectively. In the plots (b) and (d), magenta, 482 black, and green curves represent the total $\mathrm{C}$, free-C, and bonded carbon (labeled ' $\mathrm{C}$ in $\mathrm{Zr}-\mathrm{C}$ ') 483 contents in the $\mathrm{Zr}-\mathrm{C}$ samples, respectively. 

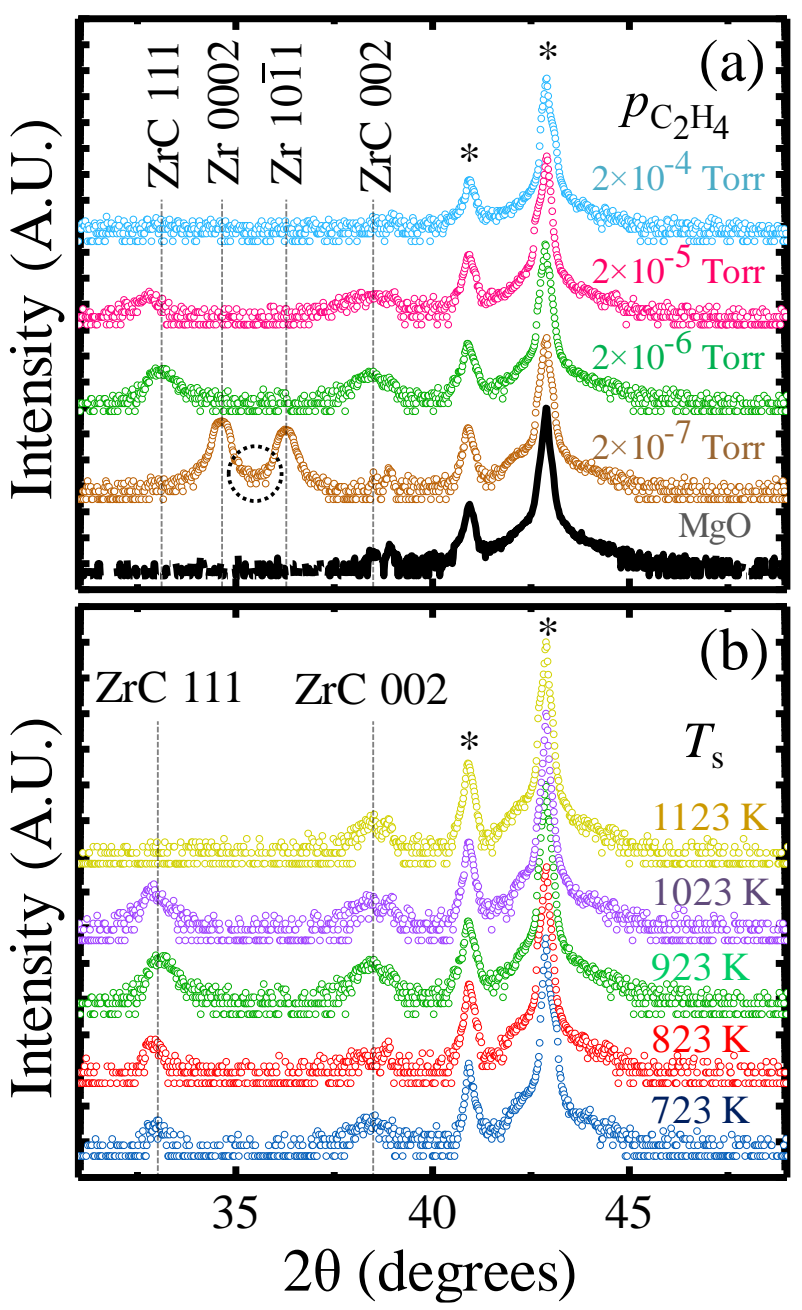

487 Figure 1 

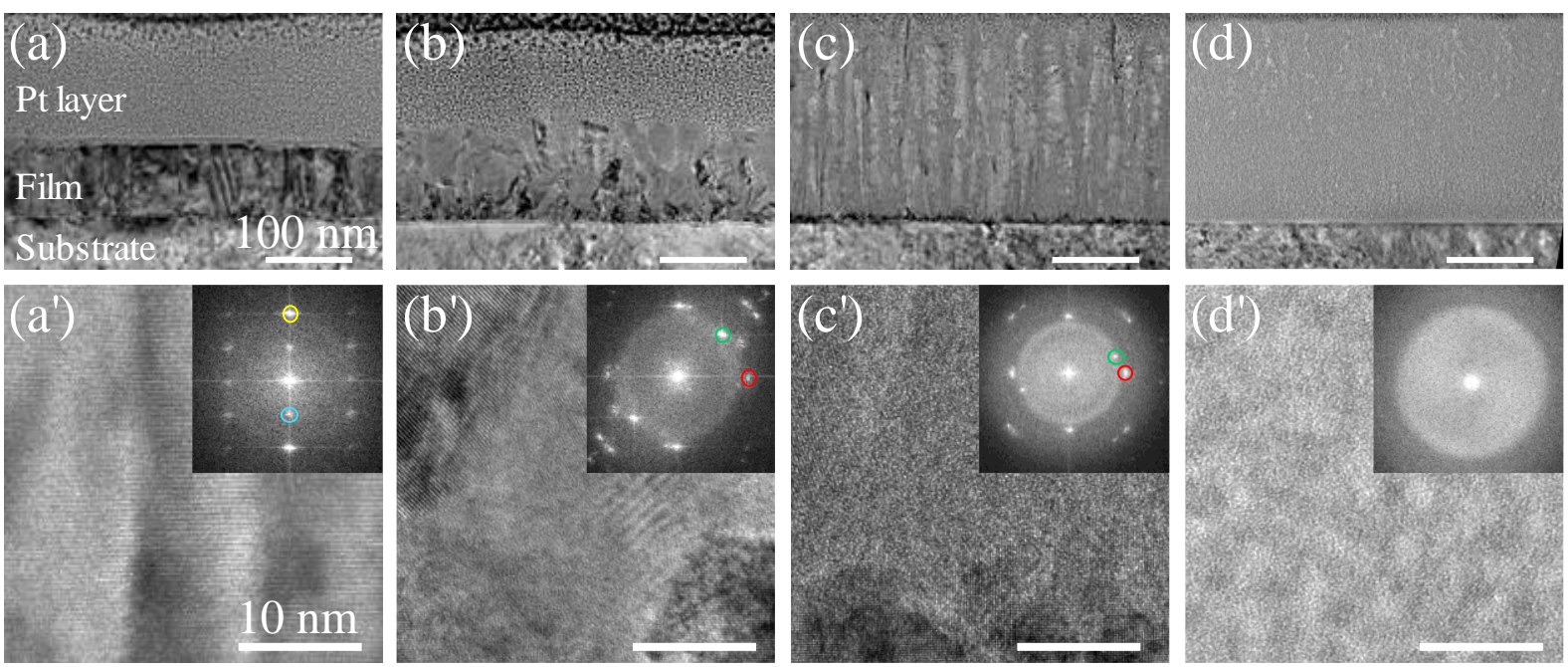

$491 \quad$ Figure 2

492 

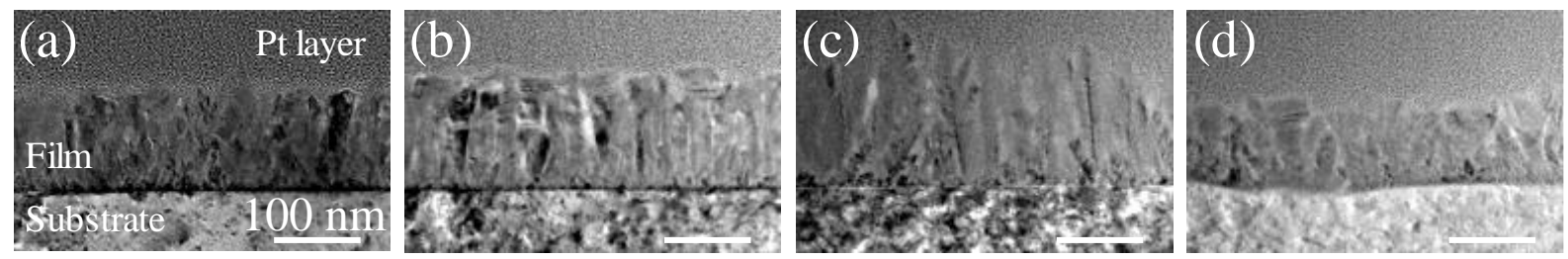

494
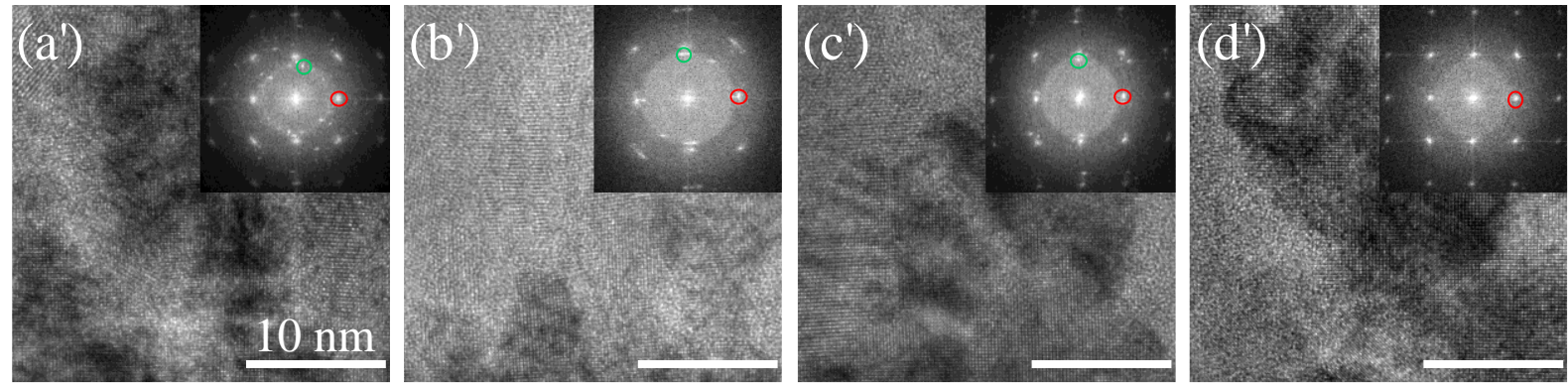

$495 \quad$ Figure 3

496 

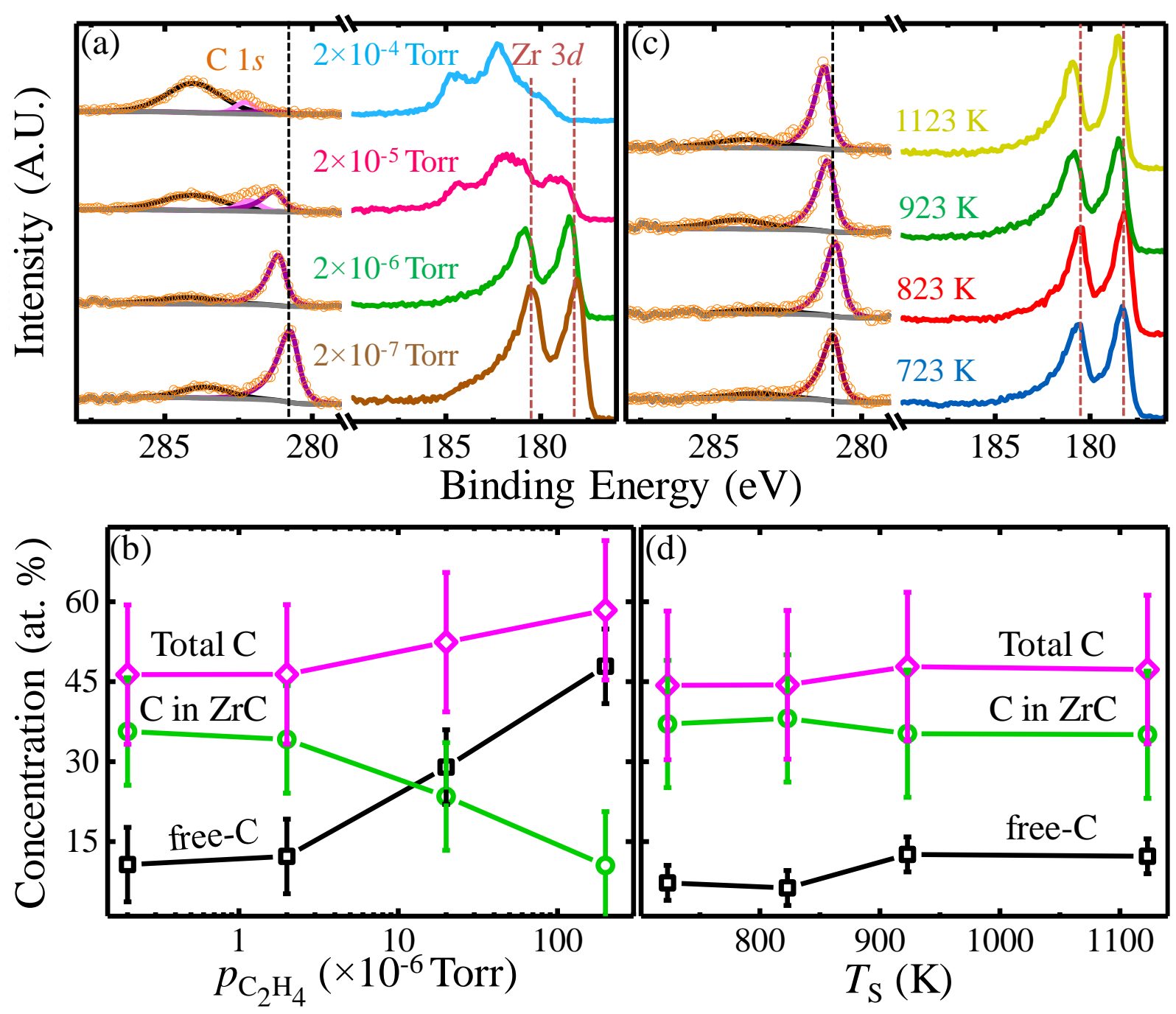

Figure 4 